\title{
Correction to: A Large-Scale Naturalistic Evaluation of the AIM Curriculum in a Public-School Setting
}

\author{
Mark R. Dixon ${ }^{1}$ - Dana Paliliunas ${ }^{2}$. Jennifer Weber ${ }^{3} \cdot$ Ayla M. Schmick $^{4}$
}

Published online: 9 December 2021

(c) Association for Behavior Analysis International 2021

\section{Correction to: A Large-Scale Naturalistic Evaluation of the AIM Curriculum in a Public-School Setting https://doi.org/10.1007/s40617-021-00569-5}

This article was updated to correct the affiliations of authors Dana Paliliunas and Ayla M. Schmick.

Publisher's Note Springer Nature remains neutral with regard to jurisdictional claims in published maps and institutional affiliations.

The original article can be found online at https://doi.org/10.1007/ s40617-021-00569-5

\footnotetext{
Mark R. Dixon

mrdixon@uic.edu

1 Department of Disability and Human Development, University of Illinois Chicago, Chicago, IL 60608, USA

2 Missouri State University, Springfield, MO, USA

3 Bethalto School District, Bethalto, IL, USA

4 Missouri Southern State University, Joplin, MO, USA
} 